\title{
Exploring veganism through serious leisure and liquid modernity.
}

\begin{abstract}
Understandings of leisure have progressed into a deep comprehension of the importance of intrinsic qualities that leisure creates for an. Individual choice and expression of self through food support the 'modern' paramount of personal choice and individuality. Food and dietary choices connecting to leisure and lifestyle mirror the conceptual framework of liquid modernity. The clarification of lifestyle offers an approach to explore veganism as a leisure lifestyle providing the foundation for this paper where veganism is explored using the dimensions of serious leisure.

In this exploratory paper, the serious leisure perspective will be critiqued as a framework to explore veganism, as it moves from a diet and lifestyle to a form of individual expression of identity and self, culture and leisure.
\end{abstract}




\section{Exploring veganism through serious leisure and liquid modernity.}

Since the pioneer Donald Watson coined the term 'vegan' in 1944 (The Vegan Society 2017) there has been a significant increase in the following of a vegan lifestyle. Veganism is especially topical in the UK, with the number of vegans reaching 542,000; a rise of 360\% in ten years (Mintel 2016a), and vegan organisations such as PETA (People for the Ethical Treatment of Animals) report over one million members (PETA 2016). Evidence of this growing trend is highlighted by the recent success of Veganuary 2018, (switching to a vegan diet for thirty days). It started in January 2014 with 3,300 participants increasing to 150,000 participants in 2018 (Vegan Food \& Living 2018). This once niche lifestyle, is gaining more mainstream consumer interest alongside discourses in healthism and a reframing of veganism within celebrity consumer culture (Doyle 2016). Although vegan approaches to diet differ, common to all is the commitment to a plant-based diet which avoids all animal foods including meat, dairy, eggs and honey (The Vegan Society 2017). It is argued more recently however, that veganism is about more than just what people eat (Mintel 2016b) and is rather an expression of individual choice through food. There remains limited recognition of the complexities of the sets of practices and meanings which constitute veganism. Researchers such as Cherry (2006; 2015), Greenebaum (2012) and Ciocchetti (2012) have provided a useful insight exploring motivations of vegans and their identity, but research into veganism as a lifestyle choice is limited. The primary research objective of this paper is to explore veganism as a serious leisure pursuit within the context of liquid modernity (Bauman 2000).

This qualitative research paper explores a more holistic account of veganism outside the disciplines of gastronomy and as an expansion of the serious leisure concept under our present times of liquid modernity.

\section{Vegan identities}

Veganism can be broadly defined as: 
A philosophy and way of living which seeks to exclude - as far as is possible and practicable - all forms of exploitation of, and cruelty to, animals for food, clothing or any other purpose; and by extension, promotes the development and use of animal-free alternatives for the benefit of humans, animals and the environment. In dietary terms, it denotes the practice of dispensing with all products derived wholly or partly from animals. (The Vegan Society 2017a)

Greenebaum (2012) suggests three categories to identify a vegan by their different morals, norms and values which may suggest reasons for their continued participation. The first are "ethical vegans" who are usually concerned with the philosophy of animal rights, along with other moral and ethical reasons. Second are the "environmental vegans" who want to improve the increasingly negative impact that the meat and dairy industry has been having on the environment. The last identified, are the "health vegans" who focus on how consuming a plant-based diet can improve their physical health or help towards weight loss. Other terms have been used to classify vegans into categories (e.g. conformed vegans, individualistic vegans and organised vegans) (Larssona et al. 2003). However, these are simplistic in their classification of vegans without consideration of broader lifestyle liquidities, and the fluid, fragmented nature of identities (Bauman 2000). The classification of veganism has raised questions about how and why vegans need to be defined by typologies (Greenebaum 2012, Cherry, 2006). How individuals identify what it means to them to be a vegan has also shown disparity, with Cherry (2006) finding that out of 26 self-identified vegans half adhered to the Vegans Society's set definition of what it meant to be vegan, but half created their own personal view of what veganism meant for them, often including some dietary element of animal products. This view of tailoring rather than subscribing to a fixed vegan identity suggests the potential liquidity of veganism, including identification and definition as individuals and group members.

Jun and Kyle (2012) suggest that the opportunity to express or affirm the self is at the core of an individual's commitment to leisure. The idea that the self is a common motivator of behaviour is a recurring theme within research into identity (Stets and Burke 2003). This denotes that it is not the leisure activities that an individual partakes in which form their identity, but rather that their motivation to partake in such leisure 
activities is formed by their desire to define and confirm their sense of self. With the notion of the self come possibilities for personal growth and self-development, which have long been associated with leisure practices and the meanings of leisure (Cohen 2014).

A widely accepted view of leisure experiences is that they should give a "sense of who we really are, why we matter and what else truly matters and has worth" (Ramsay 2014 p.175). It is argued that for an individual to have internal commitment, they must define themselves in line with the activity that they are committed to (Shamir 1988). Once individuals have identified themselves with the activity they are pursuing they incorporate the meanings associated with the activity into their identity and self-concept (Shamir, 1992). Stets and Biga (2003) suggest that to understand why individuals behave in certain ways you must understand what the identities that they are embracing mean to them. Increased salience of an individual's identity suggests a stronger link between behaviours that the individual performs and their identity (Stryker 1980). The concept of individuality is further explored by the five core components of Bauman's (2000) theory of liquid modernity, including, emancipation, individuality, time and space, work, and community which have some similarities with the six elements of the serious leisure framework. The transition from solid to liquid modernity suggests a movement away from the regulated normative society where the tendency was to conform. The transition to a society where the individual prevails and is a critical attribute to modern society is what Bauman describes as "difference which makes(s) the difference” (Bauman 2000, p.8).

Whilst food is often seen as a consumptive need, it is also an important site of selfmaking with culturist status, particularly among the educated middle classes where it may be seen as a privilege (De Solier 2013). The link between veganism and identity has been an important focus within literature, particularly in light of growing interest in ethical consumption and the self-presentation of morality in everyday life (Grauel 2016). Ciocchetti (2012) notes that identity can create expectations on what to eat, as well as when and how to do it. Our food choices can be understood in three dimensions; responsibility, identity and convenience (Belasco 2008). Thus, while some vegans may focus on responsibility, identity plays a strong role and can often outweigh convenience (Ciotcchetti 2012). Although the relationship between veganism and identity appears 
strong, not all research has found that identifying as a vegan is enough to sustain the practice (Cherry 2015). Maintaining participation has also been shown to be dependent on having supportive social networks and a collective social identity (Cherry 2006), as well as tools to provide skills and motivation to persist with veganism (Cherry 2015).

\section{Vegan Lifestyles and Ethos}

Lifestyles are said to embody shared patterns of behaviour, values and attitudes (Stebbins 1997a) and exploring lifestyle, can aid the understanding of "what people do and why they do it and what doing it means to them and others” (Chaney 2012, p.4). It is argued that lifestyles are being used to identify and explain the more complicated aspects of identity (Chaney 2012) by considering how one's choices influence our behaviours and values. Featherstone (1987 p.59) defines lifestyle as an "assemblage of goods, clothes, practices, experiences, appearance and bodily dispositions.” This highlights the importance of an individual's consumption practices in the formation of one's lifestyle. Giddens (1991) claims that lifestyle consumption practices enable individuals to make decisions about how to behave and who to be. This suggests a certain degree of liquidity of lifestyle and potentially ethos, where there is opportunity to rid ourselves of old identities and obtain a new replacement every time that we consume (Warde 1995).

Referring to veganism as a lifestyle has become accustomed in the literature and Haenfler et al. (2012) refer to veganism as a "lifestyle movement". This is supported by the lifestyle literature, which explains how individual consumption practices form to create a lifestyle (Featherstone 1987) along with having shared patterns of behaviour, values and attitudes (Stebbins 1997a) as akin to manifestations of veganism. Although veganism has been referred to as a cultural or social movement (Cherry 2006), to the individual it is clearly a lifestyle in which the everyday acts vegans perform contribute towards it (Featherstone 1987). Whilst acknowledging the subjectivity of leisure to the individual there is little recognition of the acts of veganism as constitutive of a leisure lifestyle pointing to the objective of this research. Wood (2016) suggests that serious leisure activities that challenge the early definitions of leisure raise fundamental issues about identity formation. Vegan identity, intrinsic benefits and shared ideology and 
ethos, however, are under-researched practices. The term 'ethos' can be generally described as the shared beliefs, habits and ideals of individuals or group members which supports the Vegans Society definition of veganism as a "philosophy and way of living" (The Vegan Society 2017a). Intrinsically linked to identity and lifestyle, the word ethos has both an individual and collective meaning (Halloran 1982). The shared culture and values that constitute the vegan ethos centre around care for animals, the environment and their health, reflective of the three categories of vegans expressed by Greenebaum (2012).

\section{Serious Leisure Perspective}

The term 'serious leisure' was introduced into the leisure literature in 1982 by Robert Stebbins and falls under a "conceptual umbrella" called the serious leisure perspective (Elkington and Stebbins 2014, p.3). This is a framework combining three core forms of leisure (serious pursuits, casual leisure and project-based leisure) which highlight their distinctive qualities, along with similarities and linkages between them (Stebbins 2007). The term 'serious pursuits' is yet another umbrella term which encompasses serious leisure and devotee work which is where "the line between work and leisure is virtually erased” (Elkington and Stebbins 2014, P.4).

The definition of serious leisure has remained static over the years, identified as a "systematic pursuit of an amateur, hobbyist or volunteer activity" that participants find fulfilling and interesting, which could lead to a "[leisure] career centred on acquiring and expressing its special skills, knowledge and experience” (Stebbins 1992; Elkington and Stebbins 2014).

The concept of serious leisure is still broadly used as the foundation to explore the concept of leisure across many fields and leisure activities. Worthington (2006, p.21) supported the importance of the serious leisure theoretical framework, suggesting it meant "the very idea of leisure was turned upside down". The perspective has gained theoretical supporters over the years (Blackshaw, 2010; Diley and Scraton, 2010). Conversely, Veal (2017, p205) suggests that the validity of serious leisure typology is questionable due to the belief "that seriousness is a continuum rather than discrete 
category” and questions whether the frameworks' claims can be substantiated. Kuentzel (2012) compares characteristics of openness and flexibility of recreation specialisms with the rigidity of the serious leisure perspective. The theoretical definition of serious leisure and the six constructs have been disputed. Veal (2017), argues that the allembracing definition needs to be considered with a more free, eclectic approach with broader leisure experience factors in mind more conducive to the liquid modern perspective. Consumption and particularly eating and drinking have yet to be formally categorised as serious leisure, falling more into Stebbins' casual leisure definition of 'immediately, intrinsically rewarding, relatively short-lived pleasurable activity requiring little or no special training to enjoy” (Stebbins, 1997, p.18). In opposition, Thurnell-Read (2016, p.18) concludes that "real ale enthusiasts are an example of "the growing number of examples of eating and drinking, as serious leisure” which perhaps begins recognition of the changing nature of the classification of both serious leisure and food/drink consumption. The framework does however continue to be the most prominent theoretical categorisation of leisure activities, which is the justification for the use of it in this study.

\section{Six qualities of serious leisure}

Shen and Yarnal (2010) believe that research into serious leisure and casual leisure has resulted in two contrasting concepts. Serious leisure is differentiated to short-term, casual or work-based leisure pursuits by being 'sufficiently substantial and interesting for the participant to find a career in" (Stebbins 1992) and can become a source of personal or group identity in ways that casual leisure cannot (Cohen-Gewerc \& Stebbins 2013). Although alternative scales have been developed (Gould et al 1982), Stebbins' definition remains the leading resource for serious leisure research, hence the use of this model to explore veganism.

The six distinctive qualities of serious leisure according to Stebbins' (2007) original work include; the possibility of the participant embarking on a leisure career in their activity that they then may need to persevere with to remain involved. A significant amount of personal effort will be invested into the activity for the participant to gain specialised knowledge or skills. Participants are likely to receive durable benefits when 
partaking in serious leisure, such as self-enrichment, self-actualisation and belongingness. Lastly, participants will become involved with a unique ethos and strongly identify themselves with their chosen activity within their sense of self (Stebbins 2007; Stebbins 1997b; Elkington and Stebbins 2014)

\section{Liquid modernity}

Stebbins’ serious leisure framework and Bauman’s liquid modernity theoretical framework are arguably part of the same cultural change and sociological development of the modern Western society. According to Bauman, since the 1960's, the idea of the solid modern society began to break down and change to a post-modernist world resulting in more liquid conditions of life and society where the unexpected should be expected, that lack of orientation, chaos and turbulence were the new societal and cultural norms.

The concept of liquid modernity has its roots in the post-modern debate, which Featherstone described as "the emergence of a new social totality with its own distinct organizing principles” (Featherstone 2007, p.3). He described it as failure of modernity rather strictly circumscribed social phenomenon (Featherstone 1997). Supporting the reflections of the post-modern, Shultz summarises that there is much debate about both its meaning and its application, but it can be identified as "any creative endeavor that exhibits some element of self-consciousness and reflexivity” (Shultz 2015, p.11). Although viewed as more radical than Bauman, Beck also supported the view that society was changing rapidly and suggested reflexive modernity meant "pluralization of boundaries has occurred with and between societies,” (Beck \& Lau 2003, p. 1) including between society and nature, which latterly supports potential motivations for veganism.

In 'Intimations of Postmodernity' Bauman offers the alternative view of postmodernism as not a failure of modernity but a dynamic continuation and development. It suggests a drastic individualisation of society and consumer freedom that challenges and extends the theory of postmodernity and results in a liquid modernity that restores individual's moral choices. This also aligns with and extends Stebbins' serious leisure framework and justifies this study of the exploration of veganism within these concepts

\section{Methods}


The general premise of the study was to explore veganism as a serious leisure pursuit within the context of liquid modernity. The study began with a deductive approach by starting with a general premise and then aimed to come to a specific conclusion through rational arguments (Walliman 2011) but differed to a traditional approach by using qualitative methods to gain understanding of the research context. The approach saw the researcher as an integral part of the research process; something that is more typical of an inductive approach (Saunders et al. 2009).

The research design emulates previous research by choosing a data collection method that has been proven to be effective in the past (Armour and Macdonald 2012). A common theme in the literature was the choice of semi-structured interviews when applying the serious leisure perspective to a particular activity (e.g. Chen and Pegg 2016; Kraus 2010; Littlefield and Siudzinski 2012), enabling the gathering of diverse data, new insights (Robson 2002) and understanding of the relationships between different variables (Saunders et al 2009). In order to build a common identity and bond with the sample, the researcher identified to the sample that she was a practicing vegan, supporting "the assumption that "differences" between the researcher and their participants should be downplayed, while likeness or "shared social identity" should be used to build connection” (MacDonald and Montford, 2014, p741). Identifying similarity of identity rather than difference or indifference, which although could be seen as a limitation, was in this research used as a key to allowing greater depth of rapport and trust between researcher and sample, and to allow a greater exploration of the liquid nature of veganism.

This study was carried out in 2017 in the UK, using a convenience sampling method to collect initial participants. After this a snowball sampling method was used to identify people who could provide knowledge and insight on the topic. Participants allowed the researcher to use their real name throughout the research as part of the ethical approval and confidentiality agreement.

The criterion for the participants being interviewed included being over the age of 18 and required them to have been following a vegan diet or lifestyle for at least six months. This was to ensure all participants had a practical amount of experience with being vegan and demonstrated their commitment to the practice (Buchanan 1985). The $1.5 \mathrm{hr}$ long interviews, of eight participants, took a narrative form, to gain a wider 
perspective of the participant's veganism and provide emotional context of what this meant to their wider individual story. The personal and in-depth nature of narrative research is described as involving 'first person accounts, life stories and turning points' and can be highly 'confessionable' (Prior 2016), which seemed suited to the liquidity of vegans' self-identification and motivations. The narrative interviews were shaped around the six qualities of serious leisure, identity, benefits and costs assuming multiple truths and uncertain reality (Shin 2014), supporting the alignment with Bauman's liquid modernity's fluid ever changing form.

As the terms and topics used in the study were highly subjective it would not be appropriate to make assumptions drawn on the explicit type of vegan or meaning of the terms (Brennen 2013) so it was left up to the participants to decide whether they would class themselves as a vegan and to explore what that meant to them. This allowed participants complete freedom in describing feelings, thoughts and experiences with veganism without having to fit into any criteria (Tinley and Kinney 2007). Codes and themes were collated from the findings in the secondary research using a process of data reduction to simplify and focus the coded data and analysed according to the six qualities of serious leisure as conceived by Stebbins (1992).

\section{Findings}

\section{Durable Benefits of Veganism}

Historical research has explored the perceived durable benefits of serious leisure, such as health (e.g. Kim et al 2014; McAuley and Rudolph 1995), well-being (e.g. Stebbins 1997b, Stebbins 2014), happiness (e.g. Snyder and Lopez 2007) and personal growth (e.g. Heo et al. 2014). Stebbins (1997b) notes how the rewards or benefits achieved are mostly personal and happen on an intrinsic level. Individuality and health are also areas that Bauman discusses, in combination with fitness, in Liquid Modernity (2000). He suggests that health, once solid in its objective measures of physical wellness of the body, has now been severely shaken and what constitutes a 'healthy regime of life no longer stands still’' (Bauman 2000, p.79). 
Most of the respondent's highlighted intrinsic benefits of veganism were commonly grounded in self-enrichment, happiness and improved health. For example, Megan stated that:

"It has allowed me to be happy within myself. Happy with myself"

Synder and Lopez (2007) suggest leisure generates happiness in individual's lives. Participants noted improved happiness was gained from knowing they are not causing harm to any animals, something they held as important. However, others reported how seeing results of self-enrichment contributed towards their happiness.

All respondents claimed improvements in their physical and mental health since becoming vegan. Physically, the main benefits were stability in weight, with some respondents experiencing a reduction in weight, and a perceived shortened recovery time within sports. Mental health benefits included happiness along with feelings of being in line with their beliefs and values. This supports Cherry's (2006) alignment of veganism as an individual social movement based not on politics but on adhering to individual practices within participants lifestyles and supports the liquid modernity concept of power belonging to the individual.

For example, Thomas states how being vegan makes him:

"in tune and in line with what I believe in, it is no stress on my sort of consciousness because I know that I am doing what I should be doing... I try to look to my health and I have never felt better... I am training better than ever, my mind feels clearer."

This supports the work of Kim et al (2014) who discuss the health benefits of serious involvement in leisure. However, it leaves room for development on Everard et al's (2000) findings on the association of physical health benefits to physical leisure activities and vice versa through both its physical and social manifestations.

Although many intrinsic benefits have been highlighted in support of Stebbins (1997b), it was in fact extrinsic benefits that were most commonly discussed and that participants felt were most important. 
Emelie: “...veganism is not about yourself it is about literally everything but yourself."

This was highlighted by the ways in which participants felt being vegan helped towards saving and improving the lives of animals as well as making a positive impact on the environment, typical of “moral vegans” (Ciotcchetti 2012). This supports Bauman’s view of the "paradoxical nature of the liquid modern individualization and the contradictory nature of the communitarian response” (Bauman 2000, p.170). Or how, as identified through this research, vegans identify as individuals but also as a greater community that includes both humans and animals.

\section{Personal Efforts - Skills and Knowledge}

For an individual to maintain 'serious' participation in an activity, a significant amount of effort is required for the individual to gain knowledge and develop a skill set for the activity (Stebbins 2007). Throughout the research all respondents noted an expansion in knowledge since becoming vegan or an acknowledged acquirement of new skills.

Respondents reported an increase in knowledge of nutrition and displayed this through complex dietary decision-making, or an awareness of broader benefits of different food types such as the therapeutic qualities of specific ingredients.

Megan: "It has taught me a lot about nutrition, which I never knew anything about... I had to go and read up about what do we need in our bodies every day so that when I make my meals it's like where is the protein coming from, where are all my oils coming from, where are my fats coming from etc."

Greenebaum (2012), classified vegans as ethical, environmental or health vegans. However, a desire to develop knowledge about nutrition and food was shared by all participants in this research suggesting the categorisations of vegans in this way may become blurred or obsolete as we see lifestyle interests and expertise overlap. 
The most common skill set that respondents discussed was cooking. As their diet changed they had found themselves developing their cooking skills to improve the taste and quality of food.

Megan: "It has made me cook and think more about the dishes rather than it just is like bung it in the oven [meaning quickly put in oven] and it can be anything. So, I think that's the biggest skill."

Rossman and Schlatter (2003) identify how factors such as skill level impact the experience and engagement someone has with an activity. Knowledge and skills were predominantly discussed by participants from a dietary perspective, suggesting use as a tool to alter their experience. Furthermore, the respondent's use of language of "made me" and "had to learn" denote that these are almost requirements of being vegan which supports the requirement of acquiring new skills in adherence to Stebbins' framework.

Although a significant amount of effort is required to gain any new skill, when questioned about the levels of effort required to maintain a vegan lifestyle, respondents typically claimed it to be reasonably low. For example, Sarah states how:

“on a day to day basis I don't think there is any effort required at all, you just cook food, you eat food and that's it"

However, once prompted to give examples of effort, respondents tended to discuss the small levels of effort initially invested, such as planning ahead and an increase in the amount of time spent shopping and educating themselves.

Thomas: "It may take a little bit more time, the initial time of having to educate yourself within a new diet and within a new market that's going to take you some effort. But then everything in life worth having is going to take some effort." 
Mandy: "At the beginning, it was hard. I had to think about everything, I had to plan everything... Plan when I was shopping. Research what shops sold what. Go through the process of weaning myself off cheese."

Although discongruity existed between the initial and prompted responses of participants, perhaps in part to counter feelings of marginality or criticisms of being vegan as too hard, when asked if the level of effort was worth it, participants unanimously agreed.

\section{Perseverance and Costs}

Perseverance refers to an individual's tendency to persist and endure in the face of difficulty (Eisenberger 1992, Markman et al. 2005), which Stebbins (2007) argues is necessary for individuals partaking in a serious leisure activity to remain involved. Stebbins (1997b) includes difficulties, along with disappointments and tensions, in what has been referred to as 'costs'. Although costs can be felt just as sharply as benefits (Stebbins 1997b), the notion of perceived costs has received limited attention (Stebbins 2007). Costs in a leisure circumstance refers to the "not-fun" aspect of the activity (Raisborough 1999, p.67), which we rarely expect to experience from an activity that we have chosen freely. Stebbins (1997b) identified how poignant costs can be to an individual and identified three types specific to serious leisure, which were "dislikes, tensions and disappointments”. Goff et al. (1997) also concluded that serious leisure participation could appear to negatively affect the well-being of family which could be identified as a tension between family members.

Many participants noted how veganism caused tension between participants and their family members, friends or loved ones.

Sarah: “... I went vegan when I was married, it definitely caused friction because my ex-husband was a massive meat eater... We were cooking separate dinners and eating apart at different times"

Jake: "I was sitting down one day with one of my flat mates and they were eating steaks ...I was picturing these cows being slaughtered right in front of me 
and they were the cows that they were eating and then I mentioned that and they were horrified... Not only did I feel awful about myself about these animals but I also made these people that I care about feel awful... Everything was tense."

Although Goff et al. (1997) examine serious leisure negatively affecting family members, the findings of this study expand on the theory by also exploring it in relation to friends, which is arguably highly relevant for the younger generation of vegans. All respondents discussed costs of being vegan which they needed to overcome in order to pursue veganism fully. These fell into two main categories; frustrations and tensions. Many participants expressed moments of frustration, mostly around accessibility of vegan produce and meals.

Megan: "So nothing is easily available... you have to actively search for vegan products... and that's annoying and it is frustrating. And it is also more expensive..."

Although participants demonstrate a strong overtone of frustration within veganism as their most common hardship Stebbins (1997b) fails to consider frustration in the serious leisure theory. While 'disappointments' is a category that could potentially encompass frustration, the classification of costs within serious leisure may still need to be developed in order to explore different considerations where activity components are not easily accessible.

The emergence of vegan brands, which are becoming widely available and accessible supports Bauman's assertion that the relationship between producers and consumers has been reversed, and consumerism is a driving force of society that means "liquid life is consuming life” (Vogel \& Oschmann 2013, p. 65).

\section{Identity}

The link between leisure and social identity is one that is often discussed among the serious leisure literature and is arguably one of the most prominent of the six qualities. Without a strong identification with the activity in question, it is unlikely that the 
individual will feel part of a unique ethos. Jones' (2000) research into football fan identity observes that if a participant does not strongly identify themselves as a football fan then they are likely to stop supporting their team following a loss. Furthermore, perseverance and effort will be unlikely, as will a leisure career and with this, the durable benefits, meaning that Stebbins' six qualities are diminished overall. This may be reversed with a strong sense of identity, as noted in Baldwin and Norris' (1999) study of the American Kennel Club. The participants that strongly identify themselves as a "dog person”, outweighing all costs, support the other six qualities that Stebbins identifies with serious leisure, especially perseverance.

However, this research on vegan identity was mixed. Some participants identified strongly with veganism whereas others did not seem to value veganism as very important to individual identity:

Megan: "It's not really part of me, I suppose $40 \%$ of my identity if even that high, I don't really think about it."

Jake: “So I see myself as a vegan, that's pretty much my identity now... people come to know me as the vegan, that person who is vegan... Jake the American vegan."

Consensus was reached among some participants that their social identity was portrayed differently by non-vegans then it was by other vegans. These results suggest parallels with neo-tribalism, marginalisation and Blackshaw's (2008) research into football fans which concluded that consumption patterns alone provide the basis for fan solidarity. Most participants highlighted how non-vegans portray vegans in a negative manner:

Emelie: "oh [they think] they are really grumpy and annoying and militant... always want to argue and stuff."

Megan: "I know how I get kind of labelled. Hippy, a bit wacky, a bit insane. Some people think I am genuinely mad as in not in a good way, they don't get it at all." 
This differed to how participants viewed other vegans, who they perceived more positively as generally happy, loving and caring, Gammon (2014) concludes that this may reflect how an individual aspires to be perceived themselves or perhaps suggests positive feelings of group inclusion and identity.

Emelie: “...they are so happy and they just want to spread positive energy and that is what a vegan is to me."

This supports Cherry (2015), who stated that identifying as a vegan is not enough to sustain the practice. However, it challenges conventional leisure identity theories stating that an individual must define themselves in line with the activity to have internal commitment (Shamir 1988). Although identity plays a key role within the serious leisure framework, in regard to veganism the role of identity appears to be a less significant factor in comparison to other factors such as ethos.

The validity of some participant's responses may also have been affected by an ulterior motive. Some participants were extremely passionate about the promotion of veganism, therefore their motives for their responses may have been to persuade others (Mathews and Ross 2010). Due to participant resistance, it was occasionally difficult to get them to discuss negative experiences they have had with veganism and often follow up questions were necessary to enable exposure of this area.

The inconsistency of vegan individual identity in this research supports the liquid modern view of the "individual consumer, with volatile identities” (Jay 2010, p97). Featherstone qualifies that postmodernism is open to a large range of lifestyles (Bertens 1995) and it appears the liquid modernity paradox between individuality and community seems to concur with the eclectic range of vegan identities, and the continuing bond of lifestyle choice to determine group identity, as referred to in our research. 


\section{Possibility of a Leisure Career}

Those involved in a serious leisure activity, whether they are amateurs, hobbyists or volunteers, have the opportunity to find a career in their endeavour, which is concentrated on expressing their specialised skills, knowledge and experiences (Stebbins 1992).

Employed participants in this study illustrated ways in which being vegan had influenced their work practices, adapting their work practices to be more ethical.

Thomas: "If anything it has brought me away from the jewellery trade, it isn't exactly the best for the environment. I will always look for a sort of greener, more earth conscious way around it... I am just trying to be a bit more of a greener jeweller”.

Megan: "so picture your kind of riding school, using horses to make a living... it changed the way I deal with my horses hugely. Traditionally with horses it is about the human getting control of the power of the horse and now it is much more of a partnership... You ride completely with no bits, it is all completely free. So, the horses can do what they like, and the riders have to communicate completely with them"

Although veganism has less direct links to the possibility of a career than activities such as professional swimming (Hastings et al 1995) or white-water kayaking (Bartram 2001), participant's careers are being influenced by their serious participation in veganism. Stebbins (1997b) highlights the importance of applying participants acquired skills, knowledge and experiences to creating a leisure career. However, it lacks reference to the application of these skills and knowledge to existing careers and its alignment with their ethos.

Each participant had a unique example of the ways that being vegan could influence a leisure career; some demonstrated a strong link to the framework by exhibiting signs of devotee work where the line between work and leisure is practically erased (Elkington and Stebbins 2014). However, for others, it indicated career paths that being vegan 
prevented them from pursuing. With strong correlations between veganism and participant's current or future career choices being demonstrated, development is required within the serious leisure theory to explore the different aspects in which serious leisure participation can influence their career.

\section{Vegan Ethos and Lifestyle}

Participant's ethos and ideology about veganism was passionately discussed with participants keen to share their thoughts about what veganism meant to them, including the values and beliefs that they hold.

Megan: "my idea of veganism is a love for our planet in every single way. And a respect for our planet in every single way. So far that we put ourselves as equal rather than as a higher being. That everything and everyone on our planet is as equal to us. So, nothing deserves to die just for us to live."

Valeria: "Someone that is vegan does not take anything from animals... They will put animals equal to themselves ... you don't think of yourself as a superior kind of species.”

The values and beliefs detailed participants shared qualities, as prior research by Greenebaum (2012) suggests, of caring for the environment, animals and their health. A care and concern for the animals was the most prolific value for participants, as addressed by Larssona et al (2003), while a concern for their personal health or benefits was discussed in less detail. A strong emphasis on the value of equality between themselves, the animals and the rest of humanity is something that was shared by most participants yet has not been extensively discussed within the veganism literature. The liquid modern society has been discussed as free of boundaries between human society and nature (Beck and Lau 2003). The participant's quotes about 'equality' and 
'oneness', of their society and lifestyle choices, suggest that vegans feel their version of society includes animals, highlighting their unique sense of identity.

As Stebbins (1997b) noted, a significant part of having a unique ethos with an activity involves being part of a social world, one which has a recognisable sphere of interest, including actors, events and organisations (Unruh 1979). However, it is the other actors in the social world which seemed to have the biggest impact on the respondents.

Jake: “if you are a vegan you need people, you need people around you to help you remember what's important... you need these people in your life to remind you and bring you back to yourself and why you are doing the things you are doing.”

As Cherry (2006) noted, vegans' commitment is about their collective social identity enrooted in their vegan ethos and social world which provides a support network. Although controversial and not without critique (Best 2013), Bauman viewed individuals as only supportive of groups that positively affect their self-concept or image. This proves true in the research, with strong social bonds apparent between vegans, but provides a dichotomy as vegans appear to be very inclusive of each other within the group but perhaps are criticised from some 'outside' of the community who do not follow the vegan lifestyle.

\section{Conclusion}

The article began with the suggestion that veganism could be classified according to the serious leisure framework within the liquid modernity context. In relation to effort, participants denoted skills and knowledge that revolved around the dietary aspect of veganism, with a need for improved cooking skills a necessity, therefore requiring further skills and proficiency in alignment with the framework. The availability and cost of vegan products was one of the main difficulties expressed by participants in which they needed to persevere. The participants, at first, were reluctant to denote veganism as being difficult, perhaps due to both the need to protect and promote veganism. Cost is a relatively underexplored aspect of serious leisure (Thurnell-Read 2015) and in this research there was evidence of both monetary and emotional costs. Perseverance and 
monetary costs may be countered by the recent commercialisation of vegan products, meaning they are more affordable and available. Emotional costs associated with veganism were found to cause tensions with friends, loved ones and family members and is supported by the findings of Thurnell-Read (2015). Wood's (2016) rock climbing study examined norms and transgression in serious leisure and observed 'fundamental issues about identity formation and the fate of community and place'. Similarly, veganism challenges the structure of 'normalised' serious leisure where adherence to more solid 'norms' may be resisted.

The paradoxical nature of individual and group identity was evident, with participants differing in what veganism meant to them. This supports the liquid modernity view that identity cannot be fixed and individual and group identity conflict. Regardless of the negatives, numerous durable benefits were found among participants which, similar to the work of serious leisure (e.g. Kim et al. 2014; Synder and Lopez 2007), revolved around intrinsic benefits such as happiness, and physical and mental health. The key disparity to these studies is that the participants emphasised their interest in how others benefited from their vegan participation, rather than themselves. Although intrinsic benefits were evident, similar to the findings of Greenebaum (2012) and Larssona et al. (2003), a care for animals and the environment was the common shared value that formed the vegan ethos. Supporting Stebbins (1997b), the study found that the social world was extremely important in this ethos, unlike previous studies on serious leisure which saw identity as the significant factor in serious leisure participation (e.g. Jones 2000; Lamont et al. 2014). This research suggests supportive networks and desire to help the wider environment also played an important role. The research supports the concept of veganism allowing for a more holistic, philanthropical view, less tied to individual benefit, encompassing wider societal identity. This supports Beck and Lau's (2003) suggestion of a lack of boundaries in liquid modernity between humans and nature.

While some participants held veganism as a strong part of their identity, others did not, which supports the alignment with Bauman's concept of liquid modernity's everchanging nature and the fluidity of identity. A common theme of marginality emerged, as highlighted by real ale enthusiasts (Thurnell-Read 2015) and Wallace (2006, p.230) who noted in his research on railway heritage volunteers that "to admit to being a 
trainspotter leaves oneself open to high levels of ridicule”. The possibility of pursuing a leisure career suggested ways in which veganism shaped participants future career goals or their current practices in work and wider philanthropical ideals rather than becoming a professional vegan.

The serious leisure perspective has remained notably unchanged over the years, with little development from Stebbins' original categories of amateur, hobbyist and volunteer (Stebbins 1992). While these classifications may have been useful in exploring activities such as white-water kayaking (Bartram 2001) or professional swimming (Hastings et al. 1995), they do not encompass the complexities that leisure lifestyles such as veganism hold.Veganism is complex and multi-faceted and aligns as part of an ever-changing liquid modernity, which for some is seen as a shared identity or community, but for others, is seen as a point of difference from the societal norm. As Wood (2016, p.263) found in his study of transgression in rock climbing; "Serious leisure participants may continue to resist the tendency towards uniformity in a context of increasingly mass culture”. This challenges Greenbaum’s (2012) identification of set typologies of vegan identity. This research suggests the serious leisure framework needs to evolve to incorporate and embrace the fluidity and liquidity of lifestyles such as veganism which reflect leisure associations of freedom, choice and flexibility (Rojek 2010). Liquid modernity has been used conceptually in this study as an addition and extension of Stebbins' serious leisure framework. Neither concept is without critique and neither provide a definition or model of 'one' veganism with one theoretical framework. However, in combination the frameworks of serious leisure and the concept of liquid modernity have allowed a further exploration of the holistic, multi-faceted nature of veganism as more than just a dietary choice.

The research highlights both the complexity and intricacy of what it means to identify as a vegan and how both the serious leisure framework and the concept of liquid modernity, require more fluidity in interpretation to adapt to these complexities.

\section{References}

Armour, K. And Macdonald, D., 2012. Research methods in physical education and youth sport [online]. Oxon: Routledge. 
Baldwin, C. and Norris, P., 1999. Exploring the dimension of serious leisure. "Love me - Love my dog!”. Journal of Leisure Research, 31, 1-17.

Bartram, A., 2001. Serious leisure careers among white-water kayakers: a feminist's perspective. World Leisure Journal [online], 43 (2), 4-11.

Bauman, Z., 2000. Liquid modernity. Oxford : Polity, 2000.

Beck, U., Bonss, W., \& Lau, C., 2003, 'The Theory of Reflexive Modernization: Problematic, Hypotheses and Research Programme', THEORY CULTURE AND SOCIETY, 2, p. 1.

Belasco, W., 2008. Food: the key concepts. New York: Berg Publishers.

Bernard, H., 2011. Research Methods in Anthropology [online]. 5th edition. Plymouth: AltaMira Press.

Bertens, H., 1995. The Idea of Postmodernism. A History. New York: Routledge.

Best, S., 2013. 'Liquid fandom: neo-tribes and fandom in the context of liquid modernity', SOCCER AND SOCIETY, 1, p. 80

Blackshaw, T., 2008. Contemporary community theory and football. Soccer \& Society, 9(3), pp.325-345 Vancouver.

Blackshaw, T., 2010. Leisure. New York, NY: Routledge/Taylor \& Francis Group Brennen, B., 2013. Qualitative research methods for media studies [online]. New York: Routledge.

Braun, V., and Clarke, V., 2006. Using thematic analysis in psychology. Qualitative 
Buchanan, T., 1985. Commitment and leisure behaviour: A theoretical Perspective. Leisure Sciences [online], 7 (4), 401-420.

Chaney, D., 2012. Lifestyles [online]. Oxon: Routledge.

Cheng, E., and Pegg, S., 2016. “If I'm not gardening, I'm not at my happiest”: exploring the positive subjective experiences derived from serious leisure gardening by older adults. World Leisure Journal [online], 58 (4), 285-297.

Cherry, E., 2006. Veganism as a Cultural Movement: A Relational Approach. Social Movement Studies [online], 5 (2), 155-70.

Cherry, E., 2015. I Was a Teenage Vegan: Motivation and Maintenance of Lifestyle Movements. Sociological Inquiry [online], 85 (1), 55-74.

Ciocchetti, C., 2012. Veganism and living well. Journal of Agricultural \& Environmental Ethics [online], 25, 405-417.

Cohen-Gewerc, E., and Stebbins, R.A., 2013. Serious leisure and individuality. McGill-Queen's Press-MQUP.

Cohen, S., 2014. Leisure, identities and personal growth. In: Elkington, S., and Gammon, S., eds. Contemporary Perspectives in Leisure. Oxon: Routledge, 197-206.

De Solier, I., 2013. Making the self in a material world: Food and moralities of consumption. Cultural Studies Review. 19 (1), 9-27

Dilley, E., \& Scraton, S. J., 2010. Women, climbing and serious leisure. Leisure Studies, 29, 125-142.

Doyle, J., 2016. 'Celebrity vegans and the lifestyling of ethical consumption', Environmental Communication, 6, p. 777, British Library Document Supply Centre Inside Serials \& Conference Proceedings

Eisenberger, R., 1992. Learned industriousness. Psychological Review, 99 (2), 248267. 
Elkington, S., and Stebbins, R., 2014. The Serious Leisure Perspective. Oxon: Routledge.

Everard, K., Lach, H., Fisher, E. and Baum, C., 2000. Relationship of activity and social support to the functional health of older adults. The Journals of Gerontology Series B: Psychological Sciences and Social Sciences, 55, 208-212.

Featherstone, M., 1987. Lifestyle and consumer culture. Theory, Culture and Society, 4 (1), 55-70.

Featherstone, M., 2007. Consumer culture and postmodernism. Sage.

Gammon, S., 2014. I Am What I Pretend To Be. In: Elkington, S., and Gammon, S., eds. Contemporary Perspectives In Leisure. Oxon: Routledge

Giddens, A., 1991. Modernity and Self-identity: Self and Society in the Late Modern Age. Cambridge: Polity Press.

Goff, S., Fick, D. and Oppliger, R., 1997. The Moderating effect of spouse support on the relationship between serious leisure and spouses' perceived leisure-family conflict. Journal of Leisure Research, 29, 47-60.

Gould, D., Feltz, D., Horn, T., \& Weiss, M. (1982). Reasons for attrition in competitive youth swimming. Journal of Sport Behavior, 5(3), 155

Grauel, J., 2016. Being authentic or being responsible? Food, consumption, morality and everyday life. Journal of Consumer Culture. 16(3) 856-869.

Greenebaum, J., 2012. Veganism, Identity and the Quest for Authenticity. Food, Culture \& Society [online], 15 (1) 129-144.

Haenfler, R., Johnson, B. and Jones, E., 2012. Lifestyle Movements: Exploring the Intersection of Lifestyle and Social Movements. Social Movement Studies, 11 (1), 120.

Halloran, M., 1982. Aristole's concept of Ethos, or If Not His Somebdoy Else's. Rhetoric Review [online], 1 (1), 58-63. 
Hastings, D., Kurth, S., and Schloder, M., 1995. Reasons for participating in a serious leisure career: Comparison of Canadian and US masters swimmers. International Review for the Sociology of Sport [online], 30, 101-117.

Heo, J., Kim, J., Lee, I. and Kim, J., 2014. Predicting personal growth and happiness by using serious leisure model. Social Indicators Research, 122, 147-157.

Jay, M., 2010. 'Liquidity Crisis: Zygmunt Bauman and the Incredible Lightness of Modernity', THEORY CULTURE AND SOCIETY, 6, p. 95.

Jones, I., 2000. A model of serious leisure identification: the case of football fandom. Leisure Studies [online], 19 (4), 283-298.

Jun, J., and Kyle, G., 2012. Gender identity, leisure identity, and leisure participation. Journal of Leisure Research, 44 (3), 354.

Kuentzel, W. F., (2012). Comment on Scott: Is integration better? Leisure Sciences, 34, 375-376.

Kim, J., Yamada, N., Heo, J., and Han, A., 2014. Health benefits of serious involvement in leisure activities among older Korean adults. Qualitative studies on Health and Well-being, 9, 1-9.

Kraus, R., 2010. "We are not strippers": How Belly Dancers Manage a (soft) stigmatized serious leisure activity. Symbolic Interaction [online], 33 (3), 435-455.

Lamont, M., Kennelly, M., and Moyle, B., 2014. Costs and Perseverance in Serious Leisure Careers [online]. Leisure Sciences, 36, 144-160.

Larssona, C., Rönnlunda, U., Johanssona, G. And Dahlgrenb, L., 2003. Veganism as status passage: The process of becoming a vegan among youths in Sweden. Appetite [online]. 41 (1), 61-67.

Littlefield, J., and Siudzinski, R., 2012. 'Hike your own hike': equipment and serious leisure along the Appalachian Trail, Leisure Studies [online], 31 (4), 465- 
486.

MacDonald, K., \& Montford, K., 2014. 'Eating Animals to Build Rapport: Conducting Research as Vegans or Vegetarians', Societies (2075-4698), 4, 4, p. 737

Markman, G., Baron, R. and Balkin, D., 2005. Are perseverance and self-efficacy costless? Assessing entrepreneurs' regretful thinking. Journal of Organisational Behaviour [online], 26 (1), 1-19.

Mathews, B., and Ross, L., 2010. Research Methods: A Practical Guide to Social Sciences [online]. Essex: Pearsons Education limited.

McAuley, E., and Rudolph, D., 1995. Physical activity, aging, and psychological well-being. Journal of Aging Physical Activity, 3 (1), 67-96.

Mintel, 2016. Healthy Lifestyles -UK- October 2016 [online]. London: Mintel Group.

Mintel, 2016. British Lifestyles: Growing Tired of Austerity - UK - April 2016 [online]. London: Mintel Group.

PETA, 2016. PETA UK 2016 Annual Review [online]. London: PETA. Available from:

http://www.peta.org.uk/wpcontent/uploads/2016/12/PETA_UK_2016_Annual_Rev iew.pdf [Accessed 29 March 2017].

Prior, MT., 2016. Emotion And Discourse In L2 Narrative Research, Bristol: Multilingual Matters, eBook Collection

Raisborough, J., 1999. The concept of serious leisure and women's experiences of the Sea Cadet Corps. Leisure Studies, 18, 61-71.

Ramsay, H., 2014. Reflective Leisure, Freedom and Identity. In: Elkington, S., and Gammon, S., eds. Contemporary Perspectives In Leisure. Oxon: Routledge, 173 184. 
Robson, C., 2002. Real World Research. 2nd edition. Oxford: Blackwell.

Rojek, C., 2010. The labour of leisure: The culture of free time. SAGE publications.

Rossman, J., and Schlatter, B., 2003. Recreation programming. Champaign: Sagamore Pub.

Saudners, M., Lewis, P. and Thornhill, A., 2009. Research methods for business students [online]. 5th edition. Essex: Pearson Education Limited.

Schultz, P., and Meleis, A., 1988. Nursing epistemology: Traditions, insights, questions. Journal of Nursing Scholar- ship, 20, 217-221.

Schultz, W.R., 2015. A note on postmodernism and Lyotard's role as

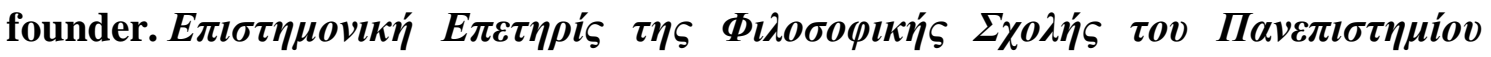

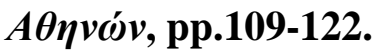

Scott, D., 2012. 'Serious Leisure and Recreation Specialization: An Uneasy Marriage', Leisure Sciences, 34, 4, pp. 366-371, Business Source Complete

Shamir, B., 1988. Commitment and Leisure. Sociological Perspectives, 31 (2), 238258.

Shamir, B., 1992. Some correlates of Leisure Identity Salience: Three exploratory studies. Journal of Leisure Research, 24 (4), 301-323.

Shen, X., \& Yarnal, C., 2010. 'Blowing Open the Serious Leisure-Casual Leisure Dichotomy: What's In There?', LEISURE SCIENCES, 2, p. 162,

Shin, S, Y., 2014. Two epistemological paradigms of self-management intervention for older adults with osteoarthritis Japan. Journal of Nursing Science [online], 11 (2), 144-149.

Schultz, W.R., 2015. A note on postmodernism and Lyotard's role as

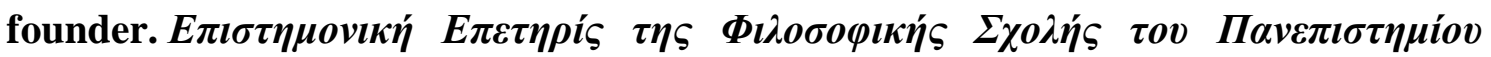

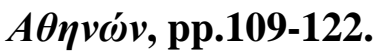


Snyder, C., And Lopez, J., 2007. Positive Psychology: The Scientific and Practical Explorations of Human Strengths. California: Sage Publications.

Stebbins, R., 1982. Serious leisure: a conceptual statement. Pacific Sociological Review, 25, 251-72.

Stebbins, R., 1992. Amateurs, Professionals, and Serious Leisure. Kingston: McGillQueen's University Press.

Stebbins, R., 1997. Lifestyle as a generic concept in ethnographic research. Quality and Quantity, 31 (4), 347-360.

Stebbins, R., 1997. Serious Leisure and Well-Being [online]. In: Haworth, J., ed. Work, Leisure \& Well-Being. Oxfordshire: Taylor \& Francis Ltd. 119-132.

Stebbins, R., 2005. Inclination to participate in organized serious leisure: An exploration of the role of costs, rewards, and lifestyle. Leisure/Loisir, 29 (2), 183201.

Stebbins, R., 2007. Serious leisure: A perspective for our time. New Jersey: Transaction.

Stebbins, R., 2014. Leisure, happiness and positive lifestyle. In: Elkington, S., and Gammon, S., eds. Contemporary Perspectives In Leisure. Oxon: Routledge, 28-38.

Stets, J., and Biga, C., 2003. Bringing identity Theory into Environmental Sociology. Sociological Theory, 21 (4), 398-423.

Stets, J., and Burke, P., 2003. A sociological approach to self and identity. In: M. Leary and J. Tangney, ed., Handbook of self and identity, 1st ed. New York: Guilford Press, 128-152.

Stryker, S., 1968. Identity salience and role performance. The importance of symbolic interaction theory for family research. Journal of Marriage and the family. 30 (5), 58-64. 
Stryker, S., 1980. Symbolic Interactionism: A Social Structural Version. Menlo Park: Benjamin Cummins.

The Vegan Society, 2017. History [online]. Birmingham: The Vegan Society. Available from: https://www.vegansociety.com/about-us/history [Accessed 5th March 2017].

Thurnell-Read, T., 2016, ' Real Ale’ Enthusiasts, Serious Leisure and the Costs of Getting 'Too Serious’ About Beer', Leisure Sciences, 1, p. 68.

Tinley, S., and Kinney, A., 2007. Three philosophical approaches to the study of spirituality. Advances in Nursing Science, 30, 71-80.

Unruh, D., 1979. Characteristics and types of participation in social worlds. Symbolic Interaction, 2, 115-130.

Veal, AJ., 2017. 'The Serious Leisure Perspective and the Experience of Leisure', Leisure Sciences, 3, p. 205, British Library Document Supply Centre Inside Serials \& Conference Proceedings

Vegan Food and Living, 2018. https://www.veganfoodandliving.com. UK (Accessed February, 2018)

Vogel, M., \& Oschmann, C., 2013, 'Cruising through liquid modernity', Tourist Studies, 13, 1, pp. 62-80, PsycINFO

Wallace, $T$ 2006, 'Working of the Train Gang': Alienation, Liminality and Communitas in the UK Preserved Railway Sector', International Journal Of Heritage Studies, 3, p. 218, British Library Document Supply Centre Inside Serials \& Conference Proceedings.

Walliman, N., 2011. Research methods: the basics [online]. London: Routledge.

Warde, A., 1995. Cultural change and class differentiation: distinction and taste in the British middle class. In: Roberts, K. (Ed.) Leisure and Social Stratification. Eastbourne: Leisure Studies Association Publication. 
Wood, M., 2016. 'On norms and their transgression in serious leisure: two case studies from rock climbing', Culture \& Organization, 22, 3, pp. 262-282.

Worthington, B., 2006. “Getting steamed up about leisure” - aspects of serious leisure within the tourism industry. In S. Elkington, I. Jones, \& L. Lawrence (Eds.), Serious leisure: $\quad$ Extensions $\quad$ and applications (pp. 1931). Eastbourne, England: Leisure Studies Association Publication.

Yoder, D., 1997. A model for commodity intensive serious leisure. Journal of Leisure Research, 29, 407-429.

Yukic, T., 1970. Fundamentals of recreation. New York: Harper \& Row. 